\title{
Critical thinking - An essential skill for English pedagogical major students: Review and applications
}

\author{
Vu Thi Hong Van ${ }^{1 *}$, Nguyen Van $\mathrm{My}^{1}$ \\ ${ }^{1}$ Ho Chi Minh City University of Education, Vietnam \\ *Corresponding author: vuthihongvandhsp@yahoo.com
}

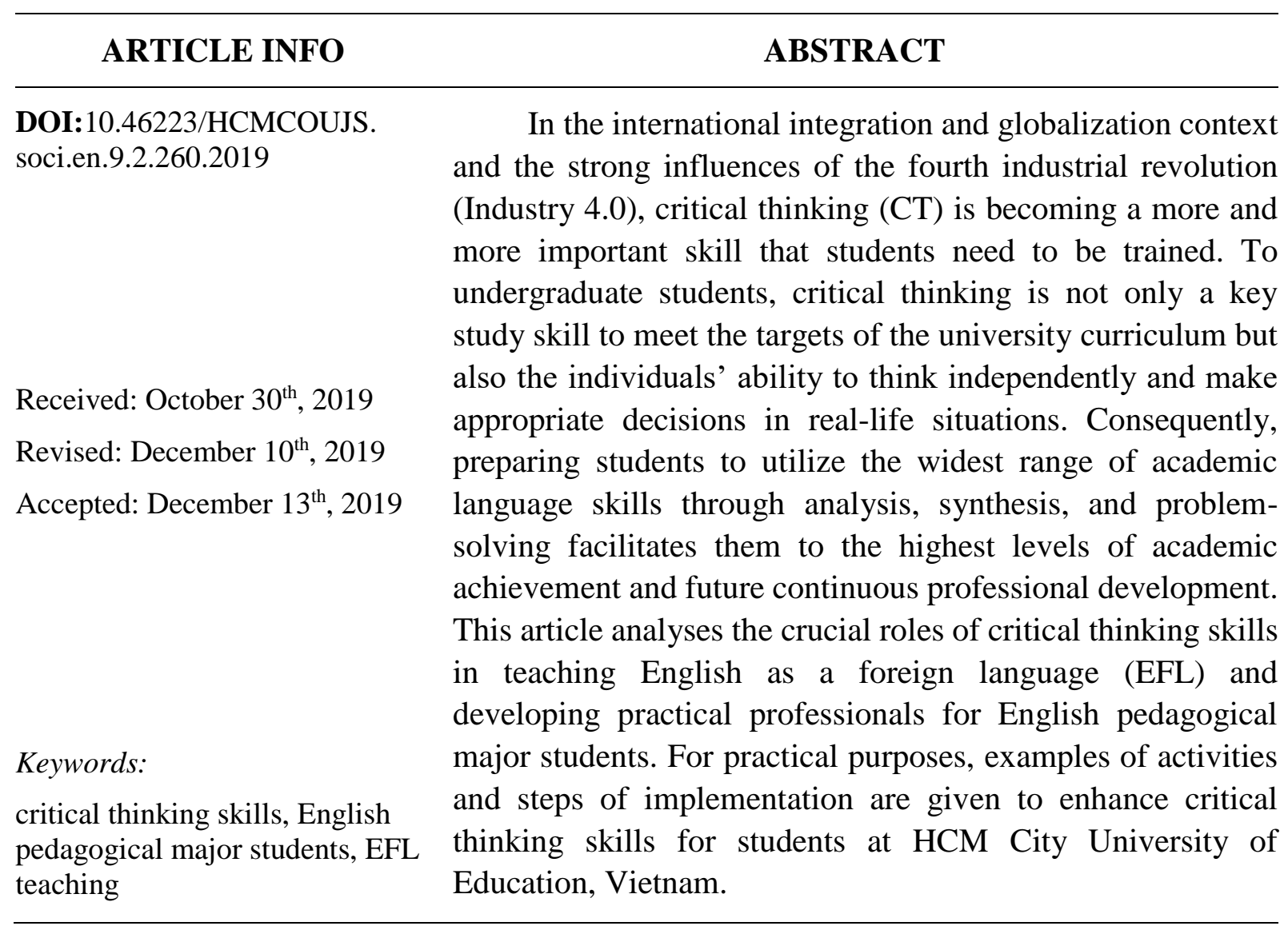

\section{Introduction}

Teaching and learning in the $21^{\text {st }}$ century contexts have slightly changed in both general and higher education. Of the various and important skills necessary for succeeding in universities, critical thinking, one of the $21^{\text {st }}$-century skills along with entrepreneurship, problem-solving and digital competencies, have been the essential skills for students. How students can apply or transfer the knowledge they gain from school or university into real-life situations is the focus of an education. Besides the basic knowledge and skills, students need to be trained and developed essential skills such as IT knowledge, communication, time management, or team-working skills, to adapt themselves to the fast-changing working environment. What students are trained and learned at university will be important for their further professional development.

For students of pedagogical majors, critical thinking ability plays an important role in their future professional development. A good teacher, in our view, is a person who can draw a 
link between current overviews and future educational changes. Once the global economy changes, it is education to be changed immediately. Following this trend, teachers and students will be the pioneers to carry out the innovation. Consequently, students need to learn how to apply knowledge to new situations through thinking critically, analyzing information, comprehending new ideas, communicating, collaborating, solving problems, or making decisions.

To be critical thinking, students need to develop a high level of concentration, in-depth analytical abilities, and improved thought processing. In language teaching, students do not learn a language for its own sake, but through the target language - the language that they learn, they will fulfill miscellaneous tasks and inquiries, and consequently will develop numerous skills that are essentially used in real-life situations. As Richards (2006) states language should serve as the means of developing higher-order thinking or critical and creative thinking skills.

Being one of the two major pedagogical universities in Vietnam, Ho Chi Minh City University of Education has had a longstanding tradition in training human resources in the fields of pedagogical majors, and it is currently in the process of comprehensive education innovation. The training for English teachers has also changed dramatically to meet the requirements of educational reform in the current socio-economic context of Vietnam. In addition to the professional knowledge and skills that are important for continuous professional development, critical thinking is considered as a significant skill that English pedagogical major students need to be trained when they are still studying at university.

From the aforementioned arguments, in order to be the " $21^{\text {st }}$ century teachers" (Jan, 2017) who have to prepare their students for keeping up with the challenges of the future, pedagogical major students should be trained on how to think critically and creatively. Review on what critical thinking is and why English pedagogical major students need to be trained on how to think critically will be explained in more detail in the following sections.

\section{What are the critical thinking skills?}

A lot of attempts have been made to provide an insight into the definition of critical thinking. According to Bowel and Kemp (2009), critical thinking is an individual's engagement in or deciding on, or responsibility for actions they deal with in daily life. Paul and Elder (2008) argue that critical thinking is the art of analyzation and evaluation in order to be improved. Furthermore, Moore and Parker (2009) suggest that critical thinking is the careful application of reason in the determination of whether a claim is true. Similarly, Rainbolt and Dwyer (2012) define critical thinking as the skill of making a decision based on the right reasons. Alternatively, Facione (2007) proposes that the ability in interpretation, analysis, evaluation, inference, explanation, and self-regulation is the most basic concept of critical thinking. In a more comprehensive argument, Birjandi and Alizadeh (2013) state that critical thinking is a purposeful self-regulatory judgment which ends in interpretation, analysis, evaluation, and inference.

Shirkhani and Fahim (2011) conclude that critical thinking refers to the individuals'

ability to think and make correct decisions independently. As critical thinkers, students should have any skills in thinking such as interpreting, analyzing, evaluating, explaining, sequencing, reasoning, comparing, questioning, inferring, hypothesizing, appraising, testing and generalizing. 


\section{Why are critical thinking skills essential for English pedagogical major students?}

As mentioned before, in the international integrated and global context as well as the strong influences of the fourth industrial revolution (Industry 4.0), there is a massive change in the framing of references about the ways of life, work, society and how every individual is viewed and organized. The gap between academic knowledge that students learn at university and the knowledge that they need in real-life situations is more and more widening. Consequently, English pedagogical major students need to prepare for themselves the adaptability skills to deal with the fast-changing requirements of society and the workplace. In this situation, problem- solving skills, group-working skills to accomplish the task of thinking critically about some problems, issues or claims need to be trained.

Some arguments are emphasizing the roles of critical thinking in the professional development of English major students. Language learners with critical thinking ability can think critically and creatively to achieve the goals of the curriculum, and then apply their critical thinking skills in real-life situations to make decisions and solve any emerging problems effectively, even when they are studying at university (Shirkhani \& Fahim, 2011). In addition to university success, Hughes (2014) argues that the skills associated with critical thinking can be linked to the students' future professional success.

\section{How to enhance the English pedagogical major students' critical thinking in EFL classrooms}

In language teaching and learning, learning environments are important parts that directly affect the quality of training programs. In a language classroom, teachers play the most important role in creating environments that facilitate learning and learning outcomes. Teachers who indigenize inquiry and critical thinking should be trained to ensure the students to have these skills. As reported by Paul and Elder (2008), a well-cultivated critical thinker is the one who raises vital questions and problems, formulating them clearly and precisely, as well as communicates effectively with others in figuring out solutions to complex problems. In order to be successful, students are required to work in pairs and groups to describe the content of the discussion, identify the issues, discuss the problems and alternative solutions, to finally evaluate the whole process.

Furthermore, critical thinkers can raise questions and find pertinent answers for those questions based on the most appropriate and reliable evidence and the basics of critical thinking (Rezaei, Derakhshan, \& Bagherkazemi, 2011). According to Paul and Elder (2008), teachers might use such techniques such as case method, question and answer, project, group discussion, experiment, observation, field trip, brainstorming and different forms of drama in order to promote students' holistic development and multilateral thinking skills in teaching English as a foreign language.

In English language teaching, the methods of assessments in classrooms strongly influence what and how the learners learn. As Brown (2003) observed, language assessment is an integral part of the language teaching-learning cycle as it serves to ascertain students' attainment of learning objectives and to compare students by their performance for placement purposes. For assessment purposes in an English class, Birjandi and Alizadeh (2013) propose several suggestions for enhancing critical thinking among language learners through 
assessment practices. Of these suggestions, feedback needs to provide students with information not only about how well they have completed the activities but also how they might improve what they have done. Another requirement of feedback is that it must come from a variety of perspectives, including from students' reflection on their work, from their peers or classmates, i.e., when students reflect on one another's work, and from the teacher. For English pedagogical major students, these kinds of feedback or assessment enable them to rethink comments on their tasks from others critically and, consequently, they might independently apply in their future job, i.e., to give feedback to their students in the real contexts of English classrooms in the future.

As discussed above, to create a sustainable platform for the educational reforms in the current context of teaching and learning English in Vietnam, and fully prepare for future professional development, students need to be encouraged to think critically when studying at pedagogical universities. To illustrate how critical thinking is encouraged in an English class for English pedagogical major students, an example of the task is given below. In this example, the teacher is the lecturer of "the English Teaching Methodology" and the students are the fourth-year English pedagogical major students who are studying the subject - English Teaching Methodology.

The purpose of the example is for students of English pedagogical major to practice how to make an effective lesson plan, through which they might develop and improve their critical thinking and creative abilities in their future professional development - teaching English as a foreign language for junior high school students. The practice task should be conducted after the students have achieved the basics of the English teaching Methodology (ELT) and learn how to write lesson plans.

In the example, the English pedagogical major students are asked to practice designing an English lesson plan using the suggested pictures. The pictures are carefully selected by the teacher to suit the contents of English textbooks used in the junior high school program. The students are asked to work in groups, discuss what the pictures are, what they are used for, how and when they might be best used in the lesson, and so on.

The method of teaching is Communicative Language Teaching (Richards, 2006), which includes such main activities as Task-completion, Opinion-sharing, Information-transfer, Roleplays, or Project-based activities, involving individuals, groups, or the whole class. Technology equipment such as smartphones, computers, social networks, and apps are also used for teaching and learning English in the class. This example is particularly conducted on the following steps:

Step 1: At the beginning of the lesson, the teacher shows some pictures and asks the students to suggest what they should do with these pictures to make the lesson more interesting. The teacher firstly writes some prompts on the board, for example: "We should use these pictures in teaching students to talk about the past event "A beautiful memory in the past" because this makes students more interested in the lesson", concurrently, the teacher asks students to work on their own and consider their response to the questions - "Do you (the students of English pe dagogical major) agree or disagree with the aforementioned statement? What's your opinion?"

This activity aims at activating critical thinking skills from the students through analyzing 
information, comprehending new ideas, and then make appropriate decisions.

Step 2: The teacher asks the students to work in groups of 4-5 and discuss how to use these pictures in the lesson. This activity motivates students to practice thinking critically through discussions and debates with others. The teacher provides some prompts that are useful for the students' discussion or debates as illustrated in the table below.

\begin{tabular}{|l|l|l|}
\hline \multicolumn{1}{|c|}{ Start of answers } & \multicolumn{1}{c|}{ Answers } & \multicolumn{1}{c|}{ Reasons } \\
\hline I think that... & These pictures are good for & Because they... \\
I strongly believe & teaching writing... & - enable students to be more \\
that... & These pictures should be & motivated in learning English \\
I totally agree with... & used for an English- & grammar... \\
I disagree with... & speaking lesson... & - help an English lesson more \\
I agree with you, but I & These pictures are & attractive to junior high school \\
suggest that... & appropriate for both English & students... \\
& speaking and English & - motivate the imaginations from \\
& writing teaching... & students when learning English ... \\
& These pictures are good for \\
& an English grammar lesson \\
& about the simple past... & - make an English lesson more \\
& interesting... \\
\hline
\end{tabular}

Source: The researcher's data analysis

After the discussion, the teacher asks the students to share their ideas about how to use these pictures to make a lesson more attractive to junior high school students. Instead of discussing in groups, they are encouraged to make an oral presentation in front of the class. The teacher then encourages the students to give feedback - a kind of assessment mentioned above - on their peers' presentations.

Step 3: After the discussion, the students are asked to practice designing a lesson plan about the topic "A beautiful memory in the past". In this activity, students might utilize critical thinking skills in recognizing particular situations, and flexibly solving problems. This activity also might enable students to practice making effective lesson plans in their English teaching in the future. After completing their lesson plans, the groups take turns to demonstrate their lessons. While one group is presenting, the others are listening and then giving feedback or recommendations. Similar activities are designed and practiced throughout the semester and in this way, the students are more engaged in the activities and develop some skills such as working in teams, giving feedback on their peers' works, critical and creative thinking and so on.

To prepare well for presentations or lessons, the students also learn and practice using appropriate classroom language. For this purpose, the teacher provides the students with a list of useful language for giving presentations as given below.

\begin{tabular}{|c|c|c|}
\hline $\begin{array}{l}\text { 1.Introductions } \\
\text { Good morning/afternoon } \\
\text { everyone and thank you for } \\
\text { coming. } \\
\text { Let me introduce you to our } \\
\text { group. My name's... and this is.... }\end{array}$ & $\begin{array}{l}\text { 3. Balancing arguments 'for' } \\
\text { and 'against' } \\
\text { First of all, here are some of the } \\
\text { arguments for... } \\
\text { Next, we'd like to present some of } \\
\text { the arguments against... }\end{array}$ & $\begin{array}{l}\text { 5. Summing up and } \\
\quad \text { concluding } \\
\text { To sum up, we 've looked at } \\
\text { three main points... } \\
\text { In conclusion,... }\end{array}$ \\
\hline
\end{tabular}




\begin{tabular}{|l|l|l|}
\hline $\begin{array}{l}\text { We're each going to talk about } \\
\text { different parts of the topic. }\end{array}$ & $\begin{array}{l}\text { However, the argument against is } \\
\text { that... }\end{array}$ & \\
\hline $\begin{array}{l}\text { 2. The structure of the } \\
\text { presentation } \\
\text { First, we'll talk about... } \\
\text { Then, we're going to present... } \\
\text { And finally,... }\end{array}$ & $\begin{array}{l}\text { 4. Moving from one point to the } \\
\text { next } \\
\text { colleague who will talk about the } \\
\text { second point. } \\
\text { Moving on to the next point... }\end{array}$ & $\begin{array}{l}\text { 6. Ending the presentation } \\
\text { and inviting questions } \\
\text { That's the end of our } \\
\text { presentation. } \\
\text { Thank you for listening. Are } \\
\text { there any questions? }\end{array}$ \\
\hline
\end{tabular}

Source: The researcher's data analysis

By using many of the expressions from each section of this list, students will ensure that their presentation is planned and organized with a clear structure.

Step 4: For out-of-the-class activities, the teacher asks each group to complete a learning-project, making a video to elaborate an answer to the question "What difficulties and challenges might students and teachers face when using personal pictures in learning and teaching English as a foreign language?" In this activity, students can utilize skills in thinking (e.g., interpreting, analyzing, evaluating, explaining, sequencing, reasoning, comparing, questioning, inferring, hypothesizing, appraising, testing and generalizing) in solving problems in a particular context.

To carry out this activity, the teacher explains the task clearly to the students so that they are going to work in groups and make a video that is between 10 and 15-minute long. Following this way, all students in the groups will have participated in this video and apply something learned in the lesson to their speaking, including basic theories of the English teaching Methodology (ELT) namely teaching English grammar, teaching the four macro-skills, promoting learners' autonomy, and making lesson plans using suggested pictures.

To make a video, the teacher guides the students on how to find ideas for their video by searching for information on the Internet, or how to use some special functions on websites namely movie or TV scripts creations (e.g., www.script-o-rama.com, www.simplyscripts.com), or text-to-speech programs creations (e.g., www.research.att.com/ ttsweb/tts/demo.php, www.research.ibm.com/tts/coredemo.shtml).

After completing their projects, each of the groups will have uploaded videos on the website: https://classroom.google.com, which was created by the teacher. This website allows the teacher to make a connection with all students through their email addresses and it also enables the teacher to manage the students' tasks promptly and effectively. When accessing this website, the students will know about the task requirements and the deadline for each task, the teacher's feedback and the peers' comments on their work. This makes an interactive learning environment and the students feel comfortable to share their opinions with their peers or to discuss with their teacher. Besides, it is easier and more convenient for the teacher to evaluate 
the students' work, and the students also feel motivated and they are more engaged in learning.

The videos will be evaluated for the quality of the script, the contents, the organization, and the students' acting in the videos. For each of the evaluated categories, the students will stick the corresponding number using the four-point scale: (1) - Needs improvements, (2) - Fair, (3) - Good, (4) - Excellent. The teacher then can choose the most interesting videos from the students' works to share with other students in the class.

\section{Comments on implementation of the lesson}

From the example described above, some positive effects can be identified. One of the most outstanding effects is that the activities can be applied in a large-size class so that all students are encouraged to participate in the group projects. Furthermore, pair and group work activities enable students to develop critical thinking skills, problem-solving, collaboration, and communication. As Paul and Elder (2008) observed, to be critical thinkers, students must communicate effectively with others in figuring out solutions to complex problems. According to Birjandi and Alizadeh (2013), by becoming more cooperatives than competitors, the students are more concerned with understanding than with outcomes, and they can help each other in developing critical thinking skills as well.

Doing activities like the one in this example helps to relate the academic knowledge the students learn in the training program to the real working environment. This is because when the students practice making the lesson plans, they have to practice particular skills of an English teacher, and these skills would be useful and necessary for their jobs in the future. Also, students have more opportunities to practice their speaking skills outside the class by recording their voices. They can be more interactive with others when uploading their records on the social network as the task described in the example above. This is likely a good model for encouraging English pedagogical major students to integrate technology into their English classrooms in the future. It is quite reasonable when Jan (2017) states, for creating a highquality professional teaching force, it is important to have a high-quality professional teacher's development program that must incorporate the use of technology integration in teaching.

\section{Conclusion}

Critical thinking skill is a form of higher-order thinking skill involving students in learning to recognize or develop an argument, use evidence in supporting that argument, drawing reasonable conclusions, and using the information to solve problems. These skills are essential for students to apply the widest range of academic language skills in the highest levels of academic achievement and their continuous professional development. In order to improve the quality of English teachers, English pedagogical major students need to be trained to think critically to be more ready with the fast-changing working requirements.

\section{References}

Birjandi, P., \& Alizadeh, I. (2013). Manifestation of critical thinking skills in the English textbooks employed by language institutes in Iran. International Journal of Research Studies in Language Learning, 2(1), 27-38. 
Bowel, T., \& Kemp, G. (2009). Critical thinking: A concise guide. London \& New York: Routledge.

Brown, H. D. (2003). Language assessment principles and classroom practices. London, UK: Pearson Education.

Facione, P. A. (2007). Critical thinking: What it is and why it counts. Insight Assessment, 1-23.

Hughes, J. (2014). Critical thinking in the language classroom. Retrieved October 25, 2018, from

https://pdfs.semanticscholar.org/9087/0038e1917fc21410632815ca86a4bf391625.pdf? ga $=2.206535770 .895269780 .1571115318-2095504583.1571115318$.

Jan, H. (2017). Teacher of 21st century: Characteristics and development. Research on Humanities and Social Sciences, 7(9), 50-54.

Moore, B. N., \& Parker, R. (2009). Critical thinking (9th ed.). New York, NY: McGraw-Hill.

Paul, B. R., \& Elder, L. (2008). The miniature guide to critical thinking: Concepts \& tools. Retrieved October 28, 2018, from https://www.criticalthinking.org/files/Concepts_Tools.pdf.

Rainbolt, G. W., \& Dwyer, S. L. (2012). Critical thinking the art of argument. Boston, MA: Wadsworth.

Rezaei, S., Derakhshan, A., \& Bagherkazemi, M. (2011). Critical thinking in language education. Journal of Language Teaching and Research, 2(4), 769-777.

Richards, J. C. (2006). Communicative language teaching today. New York, NY: Cambridge University Press.

Shirkhani, S., \& Fahim, M. (2011). Enhancing critical thinking in foreign language learners. Procedia - Social and Behavioral Sciences, 29, 111-115. 